\title{
Title Carbon Nanotube Shear-Pressed Sheet Interleaves for Mode I Interlaminar Fracture
} Toughness Enhancement

\author{
Authors James J. Stahl ${ }^{1 *}$, Alexander E. Bogdanovich ${ }^{1}$, Philip D. Bradford ${ }^{1}$ \\ Affiliations $\quad{ }^{1}$ North Carolina State University Raleigh, NC, U.S.A. \\ *corresponding author:jjstahl@ncsu.edu
}

\begin{abstract}
Failure of composite laminates is often the result of "secondary" transverse stresses causing delamination. One well known approach to prevent such failure is to incorporate a distinct interleaf material into the interlaminar region in order to increase its fracture toughness and, consequently, its resistance to delamination. In the recent years various carbon nanotube (CNT) interleaves gained much attention. This work presents experimental study of the Mode I progressive fracture of carbon/epoxy composite laminates modified with high volume fraction, aligned, non-functionalized and functionalized CNT interleaves. The interleaves used here are thin solid sheets produced from vertically grown multiwalled CNT arrays by shear pressing method. A dry or resin infused sheet is integrated between prepreg plies prior to the laminate cure. The obtained results show that both dry and pre-infused CNT interleaves significantly, up to two times, increase the critical strain energy release rate of the baseline non-interleaved laminate. Two methods of functionalizing CNTs within the preform are explored: $\mathrm{O}_{2} / \mathrm{CF}_{4}$ plasma and $\mathrm{H}_{2} \mathrm{SO}_{4} / \mathrm{KnO}_{4}$ wet chemical treatments. Both methods maintain the high alignment and aspect ratio of the CNTs. Although, functionalization results in no additional $G_{I C}$ toughening compared to the non-functionalized interleaves, the characteristics of the fracture surfaces are dramatically different.
\end{abstract}

\section{Keywords}

\section{INTRODUCTION}

Composite properties may be severely degraded due to high interlaminar stresses raised near free edges, open

holes, notches, bolts, fasteners, ply drops, stiffener connections, overlap ends in adhesive joints, and other structural cases of this kind. Those high "secondary" interlaminar transverse stresses may initiate delamination which, if not arrested by inherent barriers within the composite, can propagate through the structure and result in a catastrophic failure. In addition, various incidental low-velocity and sub-ballistic 
(such as bird strikes, hail, etc.) impact events may cause so-called "barely visible damage" which, in turn, can initiate delamination. Obviously, it is hardly possible to exclude delamination initiation due to its random nature, but using special means for arresting delamination shows feasibility. Particularly, various type interleaves locally embedded between laminate plies in susceptible sites of composite structure have been implemented and showed high efficiency if properly designed and located, see the early work review [1] on this subject.

In addition to the most common toughened thermoset adhesives and thermoplastic films, many known interleaves use fiber reinforcements such as chopped fiber mats, veils, woven and knitted fabric preforms. Among more recently developed nano-scale interleave reinforcements are electrospun nanofiber mats [2-8], nanotube buckypapers [9-11] and vertically grown uncompressed/compressed nanotube arrays [12-15]. Importantly, all of the previously used carbon nanotube (CNT) interleaves had random morphology owed to their processing methods that did not involve any CNT alignment means. Contrary to that, novel CNT interleaves which are the subject of this work, are fabricated with the use of new controlled alignment processing method, called "CNT array shear pressing”.

It should be noted that, as the literature reveals, interleaving composite laminates as the method of delamination prevention or arrest, has not been always successful, and many published results show that either "high effect", "moderate effect" or even "negative effect" can be obtained (all three effects are observed within [8]) with often no convincing explanation provided on their nature. In fact, the previously studied interleaved composites were so diverse in their materials (particularly in the interleaf structural morphologies), thicknesses and mechanical properties (such as their inherent fracture toughness, failure strain and stiffness), that it is hard to reveal common trends. Besides, significant variations are seen in the specimen geometry, test setup, data collection and reduction procedures. Also, certain intrinsic effects (such as "fiber bridging") vary from material to material and from test to test, thus adding more uncertainty. The broad variation of Mode I fracture toughness test results is no different for nanofiber reinforced interleaves or CNT reinforced interleaves, although some previously reported experimental data show consistent positive effects $[14,12]$. 
In an effort to increase the bonding efficiency between a CNT and its surrounding matrix and, consequently, improve the stress transfer within the nanocomposite, two CNT functionalization methods are explored in this work. They are encouraged by the previous studies showing that those treatments add oxygen containing sidewall groups to the outer walls of the nanotubes. The added oxygen groups were shown, in turn, to improve interactions between the epoxy matrix and enhance dispersion and wetting of the CNTs [16].

In the course of this study close attention has been paid to all essential aspects of composite sample fabrication and Double Cantilever Beam (DCB) testing, in order to make as fair as possible comparison between Mode I interlaminar fracture toughness characteristics of the "baseline" (non-interleaved) and different interleaved laminated composites, and to draw experimentally substantiated conclusions.

\section{SHEAR PRESSED CNT INTERLEAVE FABRICATION}

Vertically aligned arrays of multi-walled CNTs were fabricated in-house using chemical vapor deposition (CVD) onto a quartz substrate. Growth conditions used an iron (II) chloride catalyst in an argon and chlorine atmosphere at $810^{\circ} \mathrm{C}$ with acetylene gas as the carbon source. Array height is relatively uniform across the growth surface, but can vary in the direction of gas flow up to $\pm 100 \mu \mathrm{m}$ from the height at the middle of the array. CNT arrays with height ranging from $\sim 500 \mu \mathrm{m}$ to $\sim 1500 \mu \mathrm{m}$ have been grown and used for the interleaves in our broader research, but for the part of work reported here the CNT array height was adjusted to $\sim 500 \mu \mathrm{m}$ by choosing specific growth time. A post treatment with the carbon feed gas turned off $\left(\mathrm{Ar} / \mathrm{Cl}_{2}\right.$ atmosphere) for 10 minutes helped to remove excess amorphous carbon that improved interaction amongst the CNTs and their improved interaction with the epoxy resin infused into the shear-pressed interleave preforms.

One specific method to consolidate CNT arrays (by the way, as grown it is very sparsely populated by nanotubes) was first introduced in [17] and supported by a manual device. Later on it was advanced with the development of an automated shear press device shown in Figure 1. The shear press allows for linear application of a defined force at the trajectory angle available from $0^{\circ}$ to $90^{\circ}$ (the angle is measured from horizontal direction), or in parabolic trajectory. This is achieved by computer-controlled two-directional movement of pressing plates; the upper plate moves vertically while the lower one moves horizontally. 
Optimal shear pressing angles have been determined to be between $20^{\circ}-35^{\circ}$ to avoid loss of alignment of the CNTs, especially those located near the sheet surface. Within this angle range, undesirable effects of slipping or buckling (resulting from the lower plate sliding over the surface of the CNT sheet after the peak

compression is reached) are minimized. Excessive vertical compression can be avoided by utilizing the force sensing of the device, which can be programmed to stop at a specified compression force. The product of this operation is termed a "shear-pressed sheet" (SPS). All SPS samples used in this study were only prepared under the linear force trajectory because the parabolic one (which enables for a more gentle consolidation of the structure) has not been yet optimized for variations in array height and would add more variability to the resulting SPS morphology.

The formation of the SPS from the vertically aligned array is depicted in Figure 1 and occurs in two steps: (1) shear pressing, whereby the array is "felled" and its original vertical alignment changes to a nearly horizontal, and (2) compression, during which the array with shear-induced CNT alignment is compressed with much higher force to (i) further align CNTs closer to the horizontal plane and (ii) increase the CNT volume fraction in the interleaf. The CNT inclination angle in the produced SPSs was estimated around $7^{\circ}-8^{\circ}$ with respect to horizontal plane.

As-grown CNT arrays were shear pressed at the chosen force trajectory angle of $30^{\circ}$ to a maximum force of $500 \mathrm{~N}$, which equates to $270-800 \mathrm{kPa}$ of pressure, depending on the array dimensions. The resulting thickness of produced SPS samples was $\sim 75 \mu \mathrm{m}$. It was measured for each sample using a Mitutoyo IP65 micrometer accurate to $1 \mu \mathrm{m}$. The in-plane dimensions of SPS samples were $25 \times 75 \mathrm{~mm}$ with CNT alignment induced along the $75 \mathrm{~mm}$ dimension. Figure 2 shows that dominant unidirectional CNT alignment is present in the SPS, which has thus been consolidated into a solid sheet. The sheet can be securely separated from the press plate and able to keep its integrity and shape under delicate handling. In this way, the dry CNT sheet production is complete. After that it can be either placed directly onto the prepreg (further termed as the case of "dry interleaf") or pre-infused with appropriate resin and then placed onto the prepreg (termed as the case of “infused interleaf").

\section{OXYGEN FUNCTIONALIZATION}


The first method of CNT functionalization used here is an $\mathrm{O}_{2}$ plasma treatment that adds -OH groups to the nanotube sidewalls [18] and the second is wet chemical oxidation that is shown to preferentially bond $\mathrm{COOH}$ groups with little damage to the nanotube structure often seen with wet processing [19].

(1) Plasma Functionalization - The plasma treatment procedure was taken directly from [18] and was performed on the CNT arrays prior to shear pressing. The $\mathrm{O}_{2} / \mathrm{CF}_{4}$ plasma treatment was conducted in a capacitive coupled dielectric barrier discharge atmospheric pressure plasma system. The custom-built system consists of two parallel $\mathrm{Cu}$ plate electrodes $(60 \times 60 \mathrm{~cm})$, with a spacing of $3 \mathrm{~cm}$. The plasma was operated by a $4.8 \mathrm{~kW}$ audio frequency power supply at $1.67 \mathrm{kHz}$. All treatments were carried out for $5 \mathrm{~min}$ in $1.0 \%$ oxygen $+1.0 \% \mathrm{CF} 4+98 \%$ helium gas mixture (by mass). After treatment the arrays were immediately shear pressed and placed on the prepreg laminate and infused with resin.

(2) Acidic Wet Chemical Oxidation - The chemical oxidation method was adapted from the process described in [19], which was used on dispersed nanotubes, in order to add functionalized groups to the CNTs within the SPS without sacrificing their alignment or aspect ratio. SPS were placed on top of a quartz Buchner funnel which was drawing vacuum. The SPS was then alternately rinsed with $10 \mathrm{~N} \mathrm{H}_{2} \mathrm{SO}_{4}$ and $\mathrm{K}_{2} \mathrm{MnO}_{4}$ for 30-45 minutes. SPSs were rinsed with liberal amounts of DI water in order to remove $\mathrm{K}_{2} \mathrm{SO}_{4}$ and $\mathrm{MnSO}_{4}$. It was observed that there was also a small amount of brown particulate on the SPS, which was likely to be the insoluble $\mathrm{MnO}_{2}$, despite the absence of any applied heat. The SPSs were rinsed with concentrated $\mathrm{HCl}$ to form $\mathrm{MnCl}$, which was then rinsed out of the structure with DI water. The SPSs, still on the funnel, were placed in a vacuum oven at $50^{\circ} \mathrm{C}$ for approximately 15 minutes to dry, at which point they could be removed and placed on the prepreg laminate for infusion.

Due to size limitations during the above functionalization methods, the in-plane dimensions of the functionalized SPSs were only $25 \times 25 \mathrm{~mm}$, which is $1 / 3$ the length of the other interleaves.

\section{DCB SPECIMEN FABRICATION}


Composite samples were fabricated with ten plies $\left(\left[0^{\circ}\right]_{5 S}\right.$ lay-up) of unidirectional carbon fiber prepreg (50K Sigrafil carbon fibers impregnated with TCR UF3325 epoxy resin). Five different laminates were compared with a minimum of three specimens tested per laminate: (1) "Baseline", which is a non-interleaved laminate, (2) "Dry" interleaf, which is interleaved with an as-is (non-functionalized CNT) SPS that was not pre-infused with resin, (3) "Non-functionalized" composite interleaf, which is the non-functionalized SPS pre-infused with a low viscosity epoxy resin (the resin used was Epotek 301-21), (4) "Acid-functionalized" composite interleaf, which is an SPS first functionalized using the wet chemical method of an acid activated oxygenation reaction and then pre-infused with same low viscosity epoxy resin, and (5) "Plasmafunctionalized" composite interleaf, which is an SPS first functionalized with the plasma method and then pre-infused with same low viscosity epoxy resin. The samples are further abbreviated to 'B', 'D', 'N', 'A', and 'P' respectively. The resin infusion was performed after a 5-ply prepreg stack was assembled and the dry SPS was transferred to the top of the stack. At that point the resin was heated to $90^{\circ} \mathrm{C}$ in a microwave to decrease the viscosity to $<65 \mathrm{cP}$ and spread in a thin layer over the SPS. The 5-ply prepreg stack with the SPS and resin layer on top of it was then placed in vacuum at room temperature for 10-15 minutes to promote further resin infiltration inside the SPS. After that, excess resin was removed from the SPS and the other stack of 5 pre-assembled prepreg plies was added on top. In this way, either a "dry" or an "infused" SPS interleaf was integrated at the mid-surface of the laminate between top 5 and bottom 5 plies of prepreg (as depicted in Figure 3). The laminate lay-up was allowed to rest for a period of 24 hours under a steel plate weight ( $100 \mathrm{~Pa}$ of pressure) in order to allow the infused SPS to partially cure so as to maintain its shape under curing pressure. The laminate samples were then cured in a hot pressed vacuum bag that simulates conventional autoclave processing at a pressure of $310 \mathrm{kPa}$ and a temperature of $144^{\circ} \mathrm{C}$ for a period of 2 hours per the manufacturer's instructions. Importantly, the CNT SPS reinforcement provides high dimensional stability to the interleaves in regard of their thickness and in-plane dimensions. This feature might be beneficial for practical applications in high-precision devices and structures (particularly, miniature

\footnotetext{
${ }^{1}$ An attempt was made to fabricate a "control" composite laminate sample with same pure low viscosity resin interleaf in order to observe the net effect of CNT SPS reinforcements on the Mode I fracture toughness. However, that pure resin interleaved laminate showed high dependency of the fracture toughness on even minor changes in the DCB specimen fabrication procedure. Due to this reason, those test data are not included here.
} 
ones) which require well-defined dimensions of the toughening interleaves and joining elements, the requirement that may be difficult to satisfy with traditional adhesives.

ASTM D5528 standard [20] was used when preparing composite samples for DCB testing. Specimens were cut into strips using a wet blade diamond saw and their edges were sanded smooth with 400 grit wet sandpaper. Importantly, the ' $\mathrm{B}$ ' specimens were cut from the same panel as the ' $\mathrm{D}$ ' specimens; this eliminates some processing variability between different material samples which were intended for a mutual comparison. White spray paint was applied to one edge of the DCB specimen in order to better observe crack propagation. The edge of each specimen was then etched every $200 \mu \mathrm{m}$ using a laser cutter to allow for precise measurement of crack propagation. Two steel hinges with $28.5 \mathrm{~mm}$ length and $1.5 \mathrm{~mm}$ thickness were symmetrically bonded to the sample surfaces using Henkel Hysolß EA 9309.3NA epoxy, which was rapid-cured according to Henkel instructions at $82^{\circ} \mathrm{C}$ for 1 hour. A detailed schematic of the DCB test specimen is shown in Figure 3 with the specimen properties recorded for each specimen. Here, 'L' denotes the specimen length, ' $b$ ' width, ' $h$ ' thickness, ' $a_{0}$ ' the initial delamination length, ' $\Delta a_{\max }$ ' the maximum length of delamination, and ' $\mathrm{a}_{\mathrm{h}}$ ' the length of the hinge. An $\mathrm{a}_{0}$ of $\sim 70 \mathrm{~mm}$ was used in order to achieve an $\mathrm{a} / \mathrm{h}$ ratio of $\sim 10$, and a width of $\sim 22 \mathrm{~mm}$ was used, which more closely met the ASTM standard recommended specimen geometry [20]. The initial delamination was induced using $12-\mu \mathrm{m}$ thick Teflon film; its length was precisely measured on each test specimen. The ultimate crack length $\Delta \mathrm{a}_{\max }$ was in the range of $75-85 \mathrm{~mm}$.

\section{DCB EXPERIMENTAL}

Mode I fracture toughness testing was conducted at a constant rate of displacement of $0.25 \mathrm{~mm} / \mathrm{min}$, much slower than recommended by the standard. As mentioned above, DCB testing generally followed ASTM standard [20], but there were some deviations. One of the deviations was to not unload the specimen after the first few mm of propagation as recommended by the standard. The quality of the Teflon film used to create the pre-crack and the slow testing speed negate the need for this step. Additionally, due to the observed fiber bridging effect in the control specimens during preliminary tests it was chosen to omit an optional step of wedge pre-cracking designed to negate the effect of a possible resin rich region at the crack tip which can artificially increase fracture toughness. The 2-mm long pre-crack could introduce fiber bridging which would 
have added some toughening side effect (which was noted in [21]), thus making it much more difficult to isolate the CNT SPS toughening effect, which was of principal interest in this study.

The other deviation from the ASTM standard was in the methodology applied for the recording and processing of experimental data. Figure 4 shows the experimental set-up used to record each consecutive crack propagation increment with a resolution of $200 \mu \mathrm{m}$. For a steady-state crack propagation process, the load and displacement data were recorded after every $1 \mathrm{~mm}$ crack propagation step. For the observed instantaneous crack propagation events, data were recorded to the nearest $200 \mu \mathrm{m}$ crack increments. At the moment of instantaneous crack propagation, the current level of applied displacement was paused as quickly as possible in order to mark the crack tip location (thus allowing us to determine current crack length, $a$ ). Peak load and minimum load values at the moment of crack propagation were recorded. Any additional crack advancement during the paused displacement stage was also recorded, as some additional energy could still be released (though at a smaller and gradually declining rate). The procedure allowed, in principle, to determine an "instantaneous energy release rate" by using the peak load value and the first recorded $a$ value, and a sequence of additional "gradual energy release rates" by using further recorded crack increments and their respective (lower) load values.. However, the "gradual" values are not separately reported in this work, because they appeared to be much smaller than their respective "instantaneous" values in all cases. Yet, they are mentioned here in order to draw attention to the fact that instantaneous energy release rate values would somewhat underestimate the full amount of strain energy stored by the beam arms. That portion of stored strain energy could be hidden if restarting the test too soon, before the gradual crack propagation is finished, or left unrecognized when unloading the specimen. The critical strain energy release rates, $\mathrm{G}_{\mathrm{IC}}$, presented here, were determined for each distinct crack propagation step (i.e., the total effect of instantaneous and gradual stages) using the peak load value reached at the start of crack propagation and the "final" value of $a$ $\left(a_{i}+\Delta a\right)$ measured before the specimen loading was continued. The camera was repositioned if necessary after each crack propagation step.

To study the fracture path and delamination characteristics, a dual approach was used utilizing traditional microscopy with a Motic and field emission SEM on a FEI Verios 460L. Microscopy was used to view the fracture path on the unpainted opposite side of the specimen and both fracture surfaces of the ultimately 
failed specimens. SEM samples were prepared by cutting a small sample from the undamaged composite panel at the crack tip and polishing the edge up to 2000 grit wet sandpaper. This allowed for a view of the interleaf cross section to evaluate the quality of resin infusion into the sheet. Once the cross section was viewed, the sample was fractured manually in a manner that imitated DCB loading. This allowed for a clean view of the fracture cross section in SEM.

\section{DCB DATA PROCESSING}

Load vs. displacement curves were all adjusted to "zero displacement - zero load" position, so that the slope of the curve at the initial loading stage (which is determined by the flexural stiffness of the composite beam arms) intersects with the coordinate origin of the plot. This makes all results free from the test setup variability, and was done in lieu of zeroing the load after clamping the test specimen (load was zeroed prior to clamping) as possible variation in the hinges and their attachment, specimen clamps, or curvature in the beam arms could result in inaccuracies in the recorded displacement values. Mode I critical strain energy release rate, $\mathrm{G}_{\mathrm{IC}}$, values were determined for all conducted tests according to "Compliance Calibration" (CC) method (a.k.a. "Berry's" method [22]). In addition, all other data reduction procedures recommended by the ASTM standard [20] were used and compared with the CC method. No distinct differences between the results were found. However, the CC method afforded the luxury of direct comparison with the $\mathrm{G}_{\mathrm{IC}}$ values calculated using the Beam Theory by comparing the actual parameter $n$ determined from the CC method with the value of 3 assumed in the Beam Theory. The difference was found least significant in the case of ' $\mathrm{B}$ ' type specimens. It was also concluded that the "Modified Beam Theory" and "Modified Compliance Calibration" data reduction methods yielded practically identical results, while the CC method showed a slightly smaller slope of the data. The smaller slope is desirable as a zero slope would indicate a perfectly stable value of $\mathrm{G}_{\mathrm{IC}}$.

The obtained load-displacement curves are summarized in Figure 5 for representative 1-2 specimens of each material kind. As seen, infused SPS interleaves produce different characteristic curves due to the observed much higher variability in the delamination propagation paths (those will be discussed later in the paper).

Figure 6a shows the compound of all fracture toughness results for all specimens tested; this well illustrates the observed data scatter. It has to be pointed out that in this work, unlike in traditional DCB test data 
collection and reduction (where $\mathrm{G}_{\mathrm{IC}}$ values are calculated at specific values of $\Delta \mathrm{a}$ ), test data were collected here in a manner that enabled for a high-precision monitoring of each actual crack advancement and, subsequently, measuring with high accuracy each actual crack length increment $\Delta \mathrm{a}$, rather than assuming equal consecutive increments. Obviously, this data collection approach makes it more difficult to visually distinguish among data sets corresponding to each individual specimen when all the data sets are shown on one plot as in 6a. Also, mutual comparison among different materials becomes cumbersome. To overcome these problems, the compound data subset corresponding to each material kind was further represented by a best fit smooth polynomial trendline at the point of $\mathrm{R}^{2}$ convergence. The corresponding five trendlines are shown in Figure 6b; they are commonly termed "R-curves". As seen, with the use of adopted datapoint approximation technique, the R-curves obtained for five different material cases can be compared at a glance. To avoid any possible misinterpretation, it has to be emphasized that the original load-displacement curves in Figure 5a and Figure 5b contain numerous load "jumps" at specific (non-equally spaced) displacement values corresponding to consecutive instantaneous crack increments. On the other hand, the smooth R-curves in Figure $6 \mathrm{~b}$ do not reflect on actual crack propagation instances and their respective crack increments and should be only viewed as representing some general trends in the crack propagation process common for all specimens of each material kind. To further illustrate this point, Figure 7 (a-e), show the five separate data sets and their respective trendlines; it looks like the trendlines adequately represent respective data sets (depicted by same colors). The advantages of this non-conventional data representation technique are that, having such smooth trendlines makes it possible to (i) calculate the $\mathrm{G}_{\mathrm{IC}}$ values for any desired ( equally spaced crack tip locations, (ii) use identical (although arbitrarily chosen) crack increments for all of the materials and all individual test specimens, and thus (iii) summarize and compare $\mathrm{G}_{\mathrm{IC}}$ results obtained for all tested 'B', 'D', 'N', 'P' and 'A' type laminates in a compact way as presented in Table 1.

\section{DCB RESULTS AND DISCUSSION}

Table 1 compares the percent difference in $\mathrm{G}_{\mathrm{IC}}$ values for the four interleaved laminates ' $\mathrm{D}$ ', ' $\mathrm{N}$ ', 'P', 'A'; all values are normalized to the 'B' non-interleaved laminate. Green color indicates an increase of $\mathrm{G}_{\mathrm{IC}}$ while red color indicates its decrease vs. the baseline case. In the case of ' $D$ ' laminate, the highest $\mathrm{G}_{\mathrm{IC}}$ increase of $61.4 \%$ is seen for the $7 \mathrm{~mm}$ crack length. The gradual rise up to this point closely matches the trend of the 
infused ' $N$ ' sample, but after that the ' $D$ ' case shows gradual reduction to 0 at $\sim 25$-mm crack length, and then increasingly negative trend up to the final $50-\mathrm{mm}$ crack length recorded in these tests. This gradual decline in $\mathrm{G}_{\mathrm{IC}}$, as compared to the 'B' case, in the authors' opinion is likely due to the inherent $\mathrm{G}_{\mathrm{IC}}$ increase with the crack growth for ' $B$ ' laminate due to fiber bridging effect that competes with the $\mathrm{G}_{\mathrm{IC}}$ increase owed to the SPS interleaf. Fiber bridging is well documented in the testing of unidirectional composites; it typically results in substantial "artificial" increase of Mode I fracture toughness [23-25]. The role that fiber bridging plays, if any, in adding to the toughness of the interleaved samples, is intimately dependent on the realized fracture path for each specific material; that aspect will be discussed later in the paper with support of the obtained fractography data.

' $\mathrm{N}$ ' type laminates show significant improvement in the $\mathrm{G}_{\mathrm{IC}}$ values for the whole range of crack length. Interestingly, as Table 1 shows, the resin-infused interleaf yields non-monotonic variation of the $\mathrm{G}_{\mathrm{IC}}$ improvement with increasing crack length, and the trend closely resembles that of the dry SPS case. The initial $\mathrm{G}_{\mathrm{IC}}$ increase in ' $\mathrm{N}$ ' case is $75.8 \%$, then it grows up to the peak of $104.9 \%$ for 6 -mm crack length, and after that decreases similarly to the case 'D'. However, it still holds a $46.1 \%$ increase at the crack length of $25 \mathrm{~mm}$, contrary to zero effect in the case ' $\mathrm{D}$ ' for the same crack length. The minimum of $33.4 \%$ is reached in case ' $\mathrm{N}$ ' for 35-mm crack, and after that the trend is another growth of the $\mathrm{G}_{\mathrm{IC}}$ improvement. We do not have explanation of these peculiarities at this point, although as an upward trend in an R-curve is commonly considered indicative of fiber bridging between conventional composite plies. Based on that, we hypothesize that the initial upward trend for both ' $\mathrm{D}$ ' and ' $\mathrm{N}$ ' interleaved laminates may be due to the "nano-bridging" which provides significant reinforcement to the otherwise pure resin interlayer between the prepreg plies.

\section{SEM AND OPTICAL MICROSCOPY OF FRACTURED DCB SAMPLES}

The SEM images shown in Figure 8 were taken at the midplane of the composite interleaves before testing. Figure 8a shows that no prepreg resin has reached the center region of the interleaf as the CNTs are compact but dry. Note that apparent lack of alignment is most likely a byproduct of sanding the composite surface. The infused samples show that resin has generally penetrated through the whole thickness of the interleaf, although there is still significant number of voids present which indicates that the resin infusion technique 
could be further improved. Interestingly, the plasma functionalized interleaf shows the poorest quality of infusion; it needs additional investigation to assess if this is a meaningful phenomenon or just a single composite processing artifact.

Optical microscopy was conducted on the fracture surface of the test specimens, as depicted in Figure 9. Images were taken with the Teflon film located to the left of the fracture surface, meaning the leftmost side of the fracture surface images corresponds to $a_{0}$. Figure 10 is a representative image of a ' $\mathrm{D}$ ' specimen fracture surface, and it shows a probable propagation path through and beside the CNT interleaf based on visual surface characteristics to be discussed. As the majority of the fracture surface elements show black areas on symmetric sides, it is taken as an evidence that when the crack propagates through the ' $\mathrm{D}$ ' interleaf, it should cause either CNT fracture at the crack tip or their pull-out from both parts of the SPS under separation, or likely a combination of both these effects; otherwise the CNTs would not be observed (in a nearly equal amount) on both fracture surfaces. By analogy with adhesive joints this can be classified as "cohesive failure" mechanism. As also seen, there is a small region with a dark CNT surface and a glossy grey surface (although the gloss is difficult to see in the image). This suggests that it is also possible for the delamination to deviate outside the SPS interleaf along the interface between the outer CNTs and prepreg resin; this can be accordingly classified as "adhesive failure" type. Further on, some CNTs have probably penetrated into the prepreg resin surface layer and possibly even reached to the nearest carbon fibers. An example of such alternating cohesive-adhesive crack propagation mechanism is observed in Figure 11 for the ' $\mathrm{N}$ ' interleaf. While there is obvious crack propagation through the SPS, there is also a crack deviation outside of the SPS and penetration into the composite ply. However, without more thorough micrography it is hard to conclude how deep and how frequent such CNT penetrations into the prepreg resin are. Ideally, extensive bridging of fibers which belong to adjacent composite plies by carbon nanotubes would be the best result, due to it eliminates the weakest link in the system - a pure resin interface. And, as denser the CNT bridging is, the higher interfacial fracture toughness shall be.

SEM images shown in Figure 12 and Figure 13 provide further insight into the micro characteristics of the interleaved fracture surfaces. Figure 12 shows the cross section of both fracture surfaces at $a_{0}$ for ' $\mathrm{D}$ ' and 'N' 
cases. It is clear from Figure 12a-b that CNTs are present on both fracture surfaces which confirms that delamination crack propagates through the SPS in both ' $\mathrm{D}$ ' and ' $\mathrm{N}$ ' interleave cases.

Figure 13 compares fracture surfaces for the 'D', 'N', 'A' and 'P' cases. Figure 13a shows that numerous, seemingly random, long CNT pull-outs and long resin fracture characteristics exist during crack propagation which corresponds to significant increase in $\mathrm{G}_{\mathrm{IC}}$. It is seen in Figure 13a, as indicated by arrows, that there is a distinct interface between the SPS interleaf and prepreg resin which means that the latter is unable to penetrate into the SPS structure. This relatively weak interface is likely susceptible to an "easier" crack propagation, as was also seen in Figure 10 and Figure 11 as a change in crack path to the weak interface, which results in a reduced $\mathrm{G}_{\mathrm{IC}}$. Comparing the fracture surfaces of the ' $\mathrm{D}$ ' interleaf in Figure $13 \mathrm{a}$, to the ' $\mathrm{N}$ ' interleaf in Figure 13b, it is clear that the resin infusion into SPS preform has increased the irregularity of the fracture surface. This results in increased fracture toughness for the ' $\mathrm{N}$ ' interleaf.

The fracture surfaces of the functionalized SPS interleaves are dramatically different from those of the nonfunctionalized SPS interleaves. Figure 13c-d show the presence of clean fracture of the CNTs and matrix, with uniform CNT pull-out, thus revealing a certain effect of the oxygen functional groups on the fracture behaviors. Relatively short CNT pull-outs (between 5-10 $\mu \mathrm{m}$ in length) are present in both 'A' and 'P' interleave cases. A closer look at the characteristic fracture surfaces in Figure 14 shows the differences in the CNT pull-out phenomena for the different interleaves, with longer and non-uniform pull-outs for dry and non-functionalized interleaves as in Figure 14a-d, and short regular pull-outs characterized by uniform lengths and more aligned CNTs, as in Figures 14c,f.

From the conducted microscopy studies it is apparent that pre-infusing the SPS preform with low-viscosity resin and additional functionalization of the CNTs have a significant effect on the fracture surface characteristics and delamination propagation path, which result in variations in the measured Mode I fracture toughness values. The use of pre-infused SPS introduces more variation in the delamination path which alternates between "cohesive" and "adhesive" fracture types. Even more, it can result in a complex delamination crack propagating outside of the interleaf and possibly penetrating into the adjacent composite 
ply, which results in the highest increase of the laminate fracture toughness. Functionalization of the CNTs results in a cleaner fracture surface with relatively regular, short and aligned CNT pull-outs.

\section{CONCLUSIONS}

This paper demonstrates the use of an automated system for consolidating an aligned carbon nanotube array into a SPS by simultaneously applied compressive and shear forces. Furthermore, a unique process for functionalizing the CNT sidewalls with oxygenated species is developed using a wet chemical method that takes advantage of the stability of the SPS. This functionalization method maintains the alignment and high aspect ratio of the CNTs within the SPS. The other method used is a plasma functionalization.

SPS interleaves are shown to have a significant improvement on Mode I fracture toughness of CFRP laminates measured up to $105 \%$. Pre-infusing the SPS preform with a low viscosity epoxy resin before integrating it within the laminated composite makes strong positive effect, increasing $\mathrm{G}_{\mathrm{IC}}$ by the factor $2-3$, as compared to the dry SPS interleaf case.

Surprisingly, both CNT functionalization methods used here did not show the anticipated higher $\mathrm{G}_{\mathrm{IC}}$ increase; this warrants further studies. Particularly, the bulk properties of the non-functionalized and functionalized SPS composites should be characterized and compared in order to get more insight into the load transfer mechanisms between the CNTs and the matrix.

As evidenced by the much "smoother" load vs. displacement curves, the pre-infused SPS interleaves show better ability than the non-interleaved and dry SPS interleaved laminates to resist catastrophic failure. It is possible that this will also manifest in improved fatigue resistance, which may be another important subject of future studies.

Apart from the Mode I fracture toughness performance (which is in the focus of this paper), the CNT SPS reinforcements provide high dimensional stability to the interleaves and structural joining elements. This feature may be particularly beneficial for interfaces and joints in high-precision devices and structures (particularly, miniature ones) which require very thin preforms with well-defined dimensions - the requirement that may be difficult to satisfy with traditional adhesives. 


\section{ACKNOWLEDGMENTS}

This continuing research is financially supported by U.S. Air Force Office of Scientific Research, Grant

FA9550-12-1-0170; program manager Dr. Byung-Lip Lee.

Authors are thankful to Mr. Ang Li for assistance in data collection and processing, Chuck Mooney for SEM images, and Dr. Sam Hudson and Dr. Harold Freeman concerning chemical functionalization.

\section{REFERENCES}

[1] Sela N, Ishai O. Interlaminar fracture toughness and toughening of laminated composite materials: a review. Composites 1989;20:423-35. doi:10.1016/0010-4361(89)90211-5.

[2] Li G, Li P, Zhang C, Yu Y, Liu H, Zhang S, et al. Inhomogeneous toughening of carbon fiber/epoxy composite using electrospun polysulfone nanofibrous membranes by in situ phase separation. Compos Sci Technol 2008;68:987-94. doi:10.1016/j.compscitech.2007.07.010.

[3] Zhang J, Lin T, Wang X. Electrospun nanofibre toughened carbon/epoxy composites: Effects of polyetherketone cardo (PEK-C) nanofibre diameter and interlayer thickness. Compos Sci Technol 2010;70:1660-6. doi:10.1016/j.compscitech.2010.06.019.

[4] Palazzetti R, Zucchelli a., Gualandi C, Focarete ML, Donati L, Minak G, et al. Influence of electrospun Nylon 6,6 nanofibrous mats on the interlaminar properties of $\mathrm{Gr}$-epoxy composite laminates. Compos Struct 2012;94:571-9. doi:10.1016/j.compstruct.2011.08.019.

[5] Zucchelli A, Focarete ML, Gualandi C, Ramakrishna S. Electrospun nanofibers for enhancing structural performance of composite materials. Polym Adv Technol 2011;22:339-49. doi:10.1002/pat.1837.

[6] Hamer S, Leibovich H, Green A, Avrahami R, Zussman E, Siegmann A, et al. Mode I and Mode II fracture energy of MWCNT reinforced nanofibrilmats interleaved carbon/epoxy laminates. Compos Sci Technol 2014;90:48-56. doi:10.1016/j.compscitech.2013.10.013.

[7] Arai M, Noro Y, Sugimoto K, Endo M. Mode I and mode II interlaminar fracture toughness of CFRP laminates toughened by carbon nanofiber interlayer. Compos Sci Technol 2008;68:516-25. doi:10.1016/j.compscitech.2007.06.007.

[8] Kuwata M, Hogg PJ. Interlaminar toughness of interleaved CFRP using non-woven veils: Part 1. Mode-I testing. Compos Part A Appl Sci Manuf 2011;42:1551-9. doi:10.1016/j.compositesa.2011.07.016.

[9] Lee S-H, Kim H, Hang S, Cheong S-K. Interlaminar fracture toughness of composite laminates with CNT-enhanced nonwoven carbon tissue interleave. Compos Sci Technol 2012;73:1-8.

doi:10.1016/j.compscitech.2012.09.011. 
[10] Williams J, Graddage N, Rahatekar S. Effects of plasma modified carbon nanotube interlaminar coating on crack propagation in glass epoxy composites. Compos Part A Appl Sci Manuf 2013;54:173-81. doi:10.1016/j.compositesa.2013.07.018.

[11] Almuhammadi K, Alfano M, Yang Y, Lubineau G. Analysis of interlaminar fracture toughness and damage mechanisms in composite laminates reinforced with sprayed multi-walled carbon nanotubes. Mater Des 2014;53:921-7. doi:10.1016/j.matdes.2013.07.081.

[12] Garcia EJ, Wardle BL, John Hart a. Joining prepreg composite interfaces with aligned carbon nanotubes. Compos Part A Appl Sci Manuf 2008;39:1065-70. doi:10.1016/j.compositesa.2008.03.011.

[13] Wicks SS, de Villoria RG, Wardle BL. Interlaminar and intralaminar reinforcement of composite laminates with aligned carbon nanotubes. Compos Sci Technol 2010;70:20-8. doi:10.1016/j.compscitech.2009.09.001.

[14] Falzon BG, Hawkins SC, Huynh CP, Radjef R, Brown C. An investigation of Mode I and Mode II fracture toughness enhancement using aligned carbon nanotubes forests at the crack interface. Compos Struct 2013;106:65-73. doi:10.1016/j.compstruct.2013.05.051.

[15] Wicks SS, Wang W, Williams MR, Wardle BL. Multi-scale interlaminar fracture mechanisms in woven composite laminates reinforced with aligned carbon nanotubes. Compos Sci Technol 2014;100:128-35. doi:10.1016/j.compscitech.2014.06.003.

[16] Tasis D, Tagmatarchis N, Bianco A, Prato M. Chemistry of carbon nanotubes. Chem Rev 2006;106:1105-36. doi:10.1021/cr050569o.

[17] Bradford PD, Wang X, Zhao H, Maria J-P, Jia Q, Zhu YT. A novel approach to fabricate high volume fraction nanocomposites with long aligned carbon nanotubes. Compos Sci Technol 2010;70:1980-5. doi:10.1016/j.compscitech.2010.07.020.

[18] Stano KL, Carroll M, Padbury R, McCord M, Jur JS, Bradford PD. Conformal atomic layer deposition of alumina on millimeter tall, vertically-aligned carbon nanotube arrays. ACS Appl Mater Interfaces 2014;6:19135-43. doi:10.1021/am505107s.

[19] Wepasnick KA, Smith BA, Schrote KE, Wilson HK, Diegelmann SR, Fairbrother D, et al. Surface and structural characterization of multi-walled carbon nanotubes following different oxidative treatments. Carbon N Y 2011;49:24-36. doi:10.1016/j.carbon.2010.08.034.

[20] ASTM D 5528-13, Standard Test Method for Mode I Interlaminar Fracture Toughness of Unidirectional Fiber-Reinforced Polymer Matrix Composites," in Annual Book of ASTM Standards. Vol. 15.03, American Society for Testing and Materials, 2013.

[21] Stevanovic D, Jar P-YB, Kalyanasundaram S, Lowe a. On crack-initiation conditions for mode I and mode II delamination testing of composite materials. Compos Sci Technol 2000;60:1879-87. doi:10.1016/S0266-3538(00)00080-4.

[22] Berry JP. Determination of Fracture Surface Energies by the Cleavage Technique. J Appl Phys 1963;34:62. doi:10.1063/1.1729091.

[23] Szekrenyes A. Overview on the experimental investigation of the fracture toughness in composite materials. Dep Appl Mech 2002:1-19. 
[24] Brunner AJ, Blackman BRK, Davies P. A status report on delamination resistance testing of polymer-matrix composites. Eng Fract Mech 2008;75:2779-94.

doi:10.1016/j.engfracmech.2007.03.012.

[25] Hu X, Mai Y. Mode I delamination of fibre bridging in carbon fiber epoxy composites with and without PVAL coating 1993;46:147-56.

\section{Figure Captions}

Figure 1: Automatic shear press with a graphic illustrating the process of shear pressing CNT arrays. SEM images to the right show the cross section of an array before (top) and after (bottom) shear pressing.

Figure 2: SEM images of shear pressed CNT sheet: top view (a) and cross-sectional view (b).

Figure 3: DCB Specimen schematic. Approximate specimen dimensions: $a_{h}=28.5 \mathrm{~mm}, a_{0}=70 \mathrm{~mm}, \Delta a_{\max }>$ $100 \mathrm{~mm}, L>200 \mathrm{~mm}, h=5.5 \mathrm{~mm}, b=22 \mathrm{~mm}$.

Figure 4: Experimental set-up (left) and sample image used to record a (right).

Figure $5(a, b)$ : Representative load vs. displacement curves for $B, D$, and $N$ interleaves $(a)$, and $A$ and $P$ interleaves $(b)$.

Figure $6(a, b)$ : CC fracture toughness data collected for all tested specimens (a), and best-fit polynomial trendlines for each material kind $(b)$.

Figure 7(a-e): Best-fit polynomial trendlines for baseline (a), dry (b), non-functionalized (c), acid functionalized (d), and plasma functionalized (e) material types.

Figure 8: Cross-sectional images of the center region of the ' $D$ ' $(a)$, ' $N$ ' $(b)$, ' $A$ ' $(c)$, and ' $P$ ' $(d)$ interleaves.

Figure 9: Schematic of how fracture surfaces are analyzed.

Figure 10: Fracture surface of representative ' $D$ ' specimen with schematic of typical crack path based on fracture surface characteristics.

Figure 11: Fracture surface of representative ' $N$ ' specimen with schematic of typical crack path based on fracture surface characteristics.

Figure 12: SEM of ' $D$ ' $(a)$ and ' $N$ ' (b) near crack initiation. Scale arrow denotes crack propagation direction.

Figure 13: Micro scale SEM images of ' $D$ ' $(a)$, ' $N$ ' $(b)$, 'A' $(c)$, and ' $P$ ' $(d)$ interleave cases. Scale arrow denotes crack propagation direction.

Figure 14: Approaching nano scale SEM of ' $D$ ' $(a, d),{ }^{2}(b, e)$, and ' $A$ ' $(c, f)$ interleaves near crack initiation. Scale arrow denotes crack propagation direction.

Table 1 - Percent change of $G_{I C}$ values for different interleaved laminates over the non-interleaved baseline laminate Results were obtained with the use of trendlines as in Figure 6 and Figure 7 with identical crack increments $\Delta$ a taken for all five material kinds. 
Table 1 - Percent change of $G_{I C}$ values for different interleaved laminates over the non-interleaved baseline laminate Results were obtained with the use of trendlines as in Figure 6 and Figure 7 with identical crack increments $\Delta$ a taken for all five material kinds.

\begin{tabular}{|c|c|c|c|c|}
\hline & & \multicolumn{3}{|c|}{ Infused } \\
\hline$\Delta \mathbf{a}$ & Dry & $\begin{array}{c}\text { Non- } \\
\text { Funct. }\end{array}$ & Plasma & Acid \\
\hline 0.2 & -4.9 & 75.8 & 63.9 & 100.3 \\
\hline 1 & 13.1 & 84.6 & 62.6 & 93.2 \\
\hline 2 & 30.5 & 92.8 & 61.2 & 85.2 \\
\hline 3 & 43.1 & 98.5 & 60.0 & 78.2 \\
\hline 4 & 51.8 & 102.2 & 58.9 & 71.9 \\
\hline 5 & 57.4 & 104.3 & 57.8 & 66.2 \\
\hline 6 & 60.4 & 104.9 & 56.9 & 61.1 \\
\hline 7 & 61.4 & 104.5 & 56.0 & 56.6 \\
\hline 8 & 60.7 & 103.1 & 55.1 & 52.5 \\
\hline 9 & 58.8 & 101.0 & 54.1 & 48.8 \\
\hline 10 & 55.9 & 98.4 & 53.2 & 45.5 \\
\hline 15 & 33.7 & 80.4 & 47.3 & 32.9 \\
\hline 20 & 10.7 & 61.3 & 38.4 & 25.2 \\
\hline 25 & -5.9 & 46.1 & 25.1 & 20.3 \\
\hline 30 & -14.6 & 36.7 & & \\
\hline 35 & -17.0 & 33.4 & & \\
\hline 40 & -16.0 & 35.4 & & \\
\hline 45 & -14.6 & 41.2 & & \\
\hline 50 & -15.3 & 49.1 & & \\
\hline
\end{tabular}


Figure 1
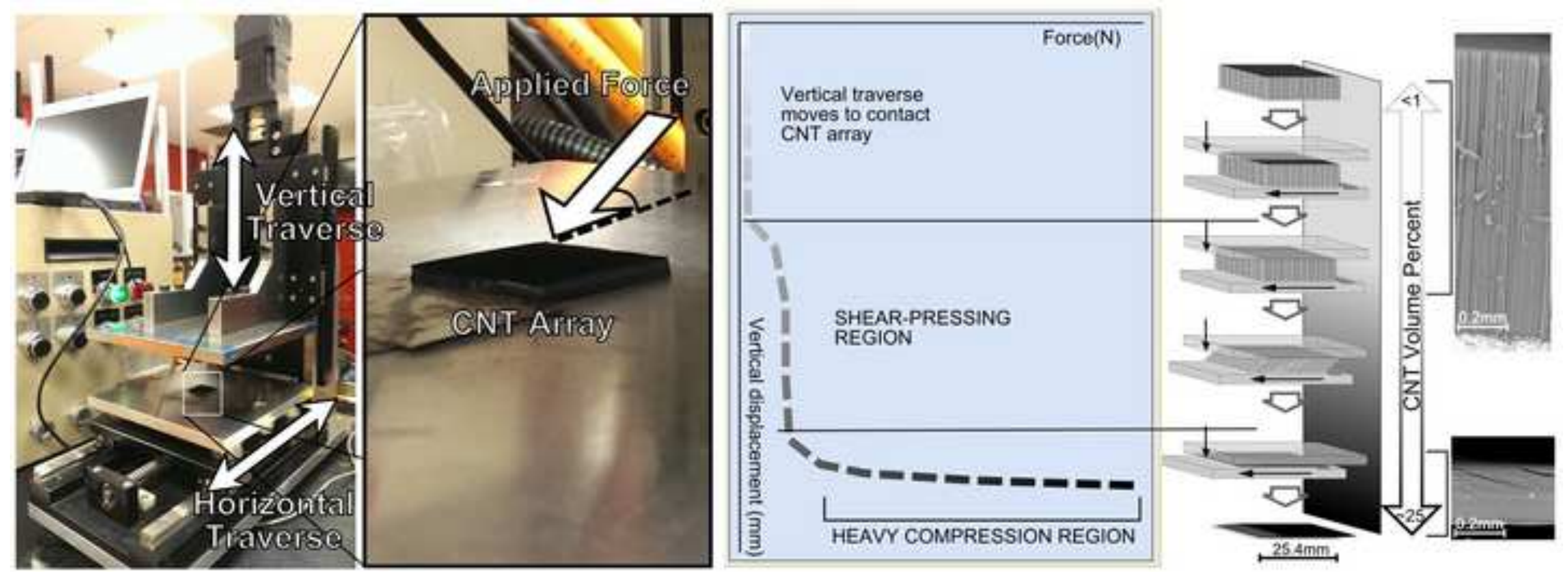
Figure 2
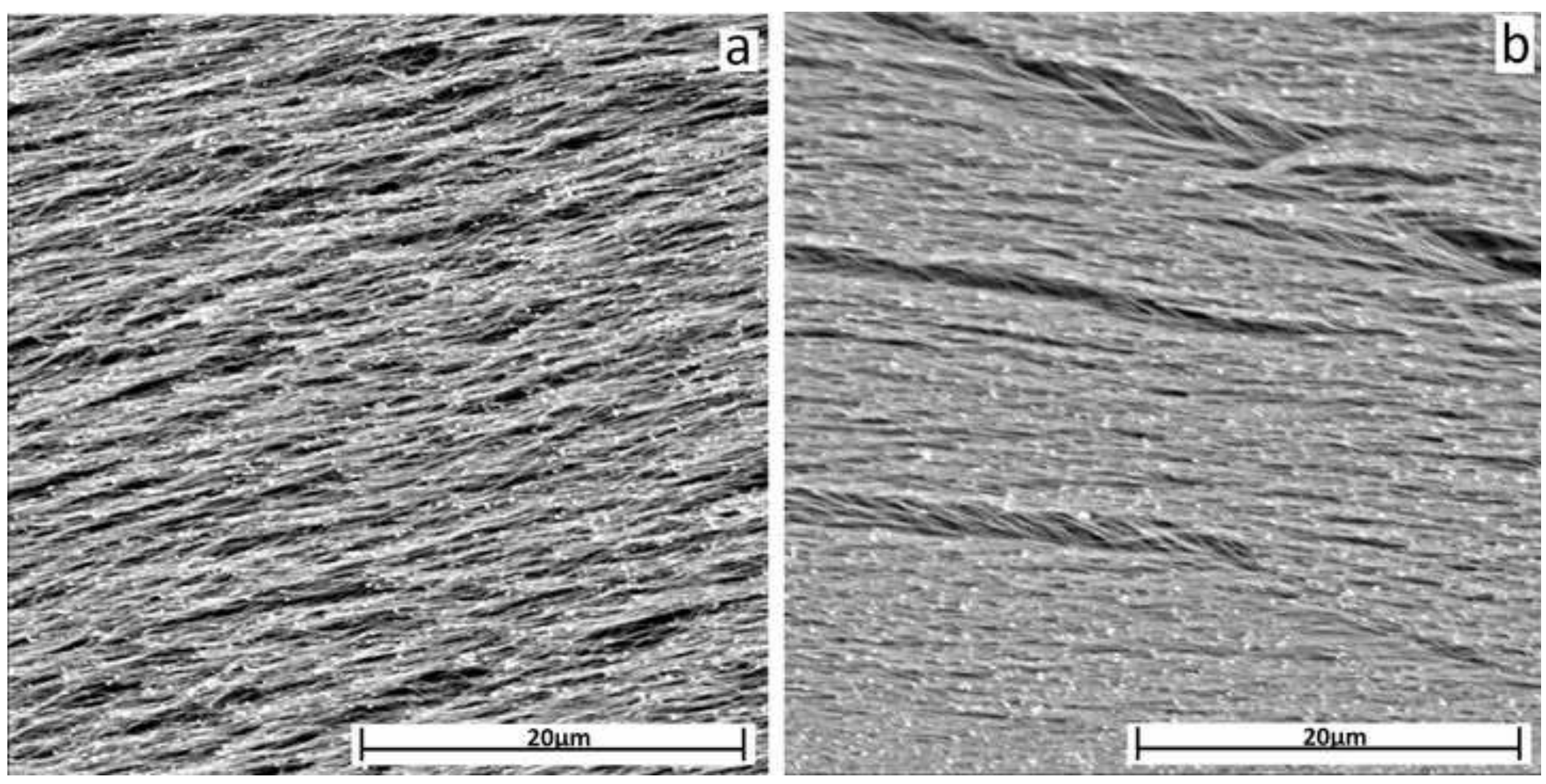
Figure 3

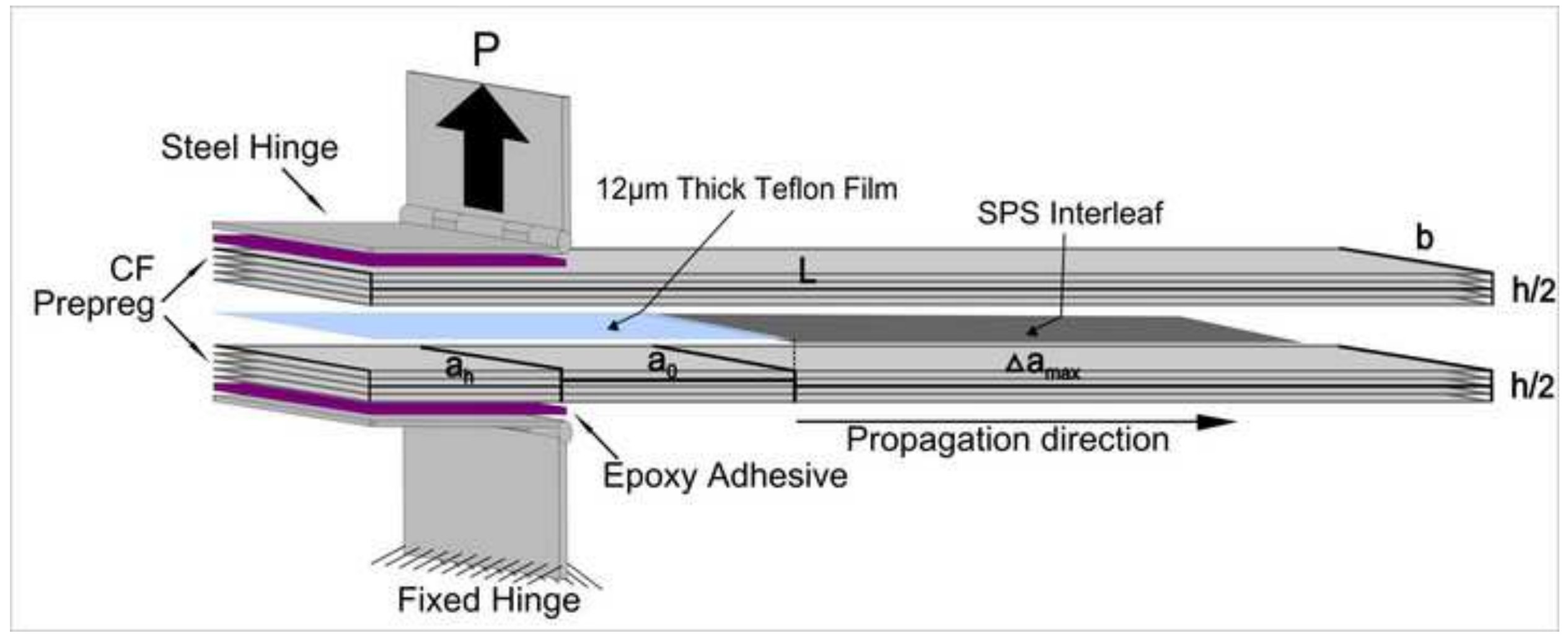


Figure 4

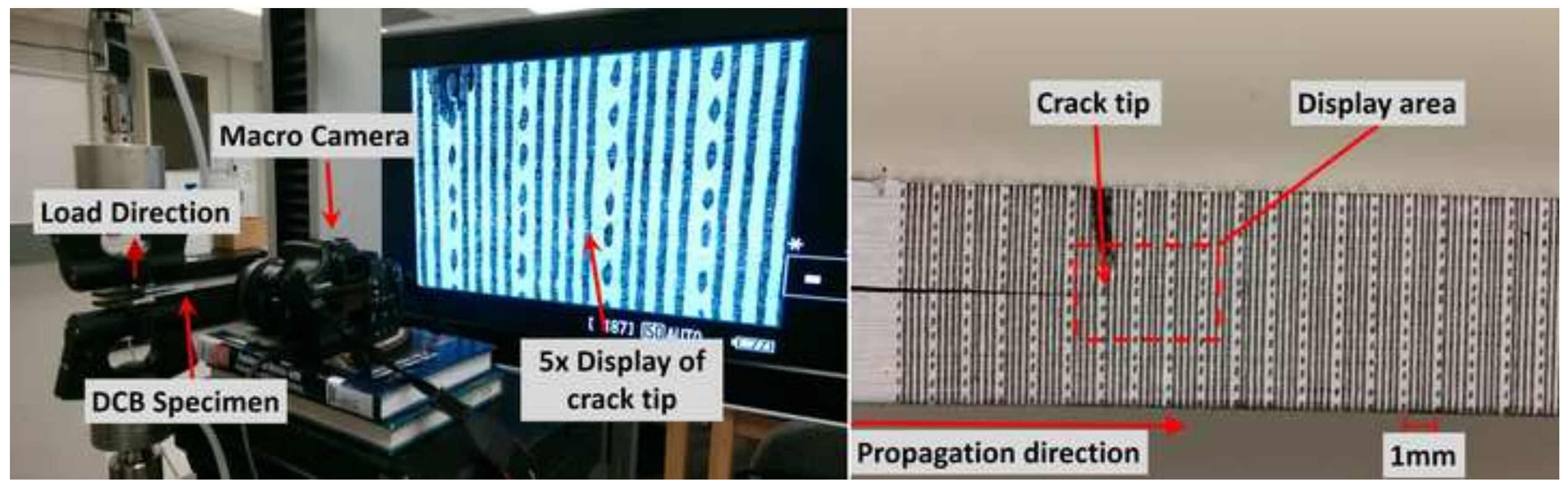


Figure 5
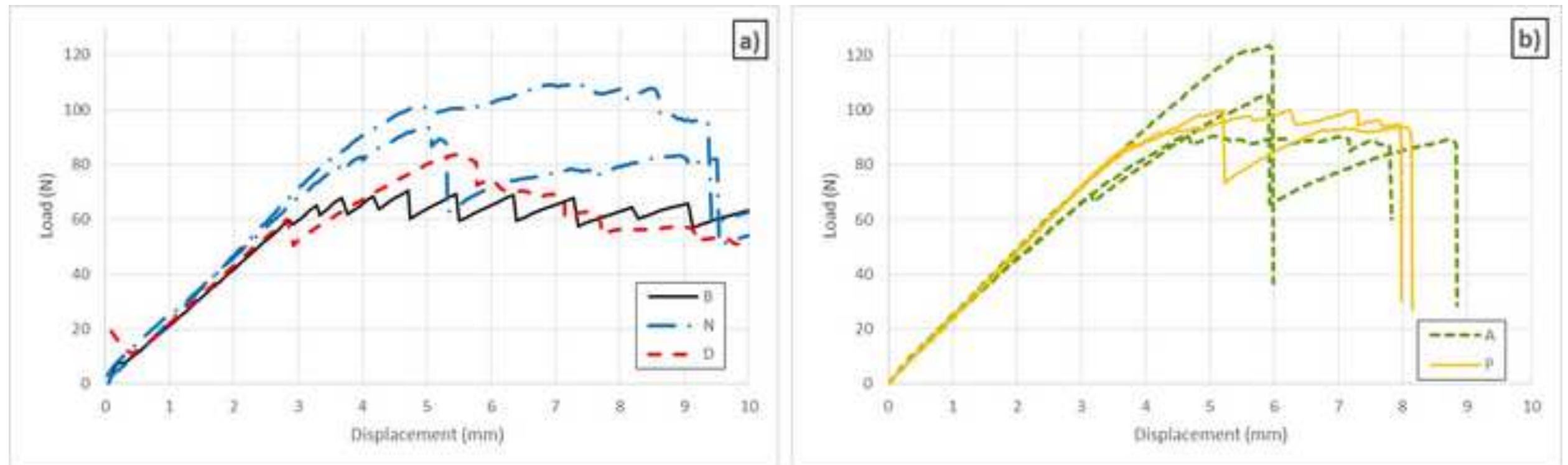
Figure 6
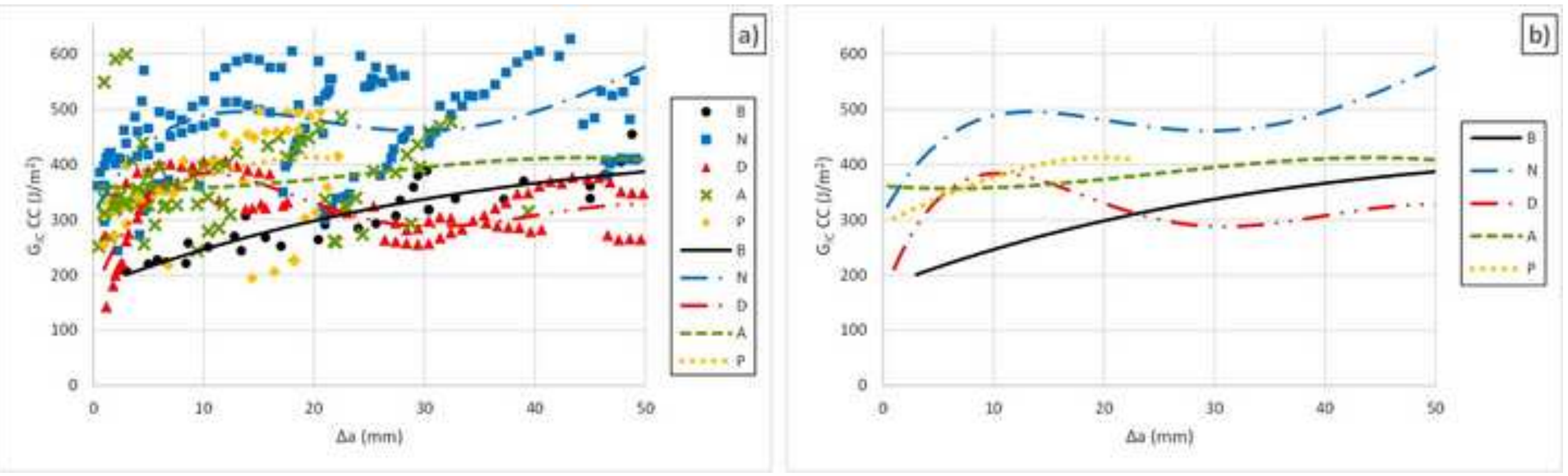
Figure 7
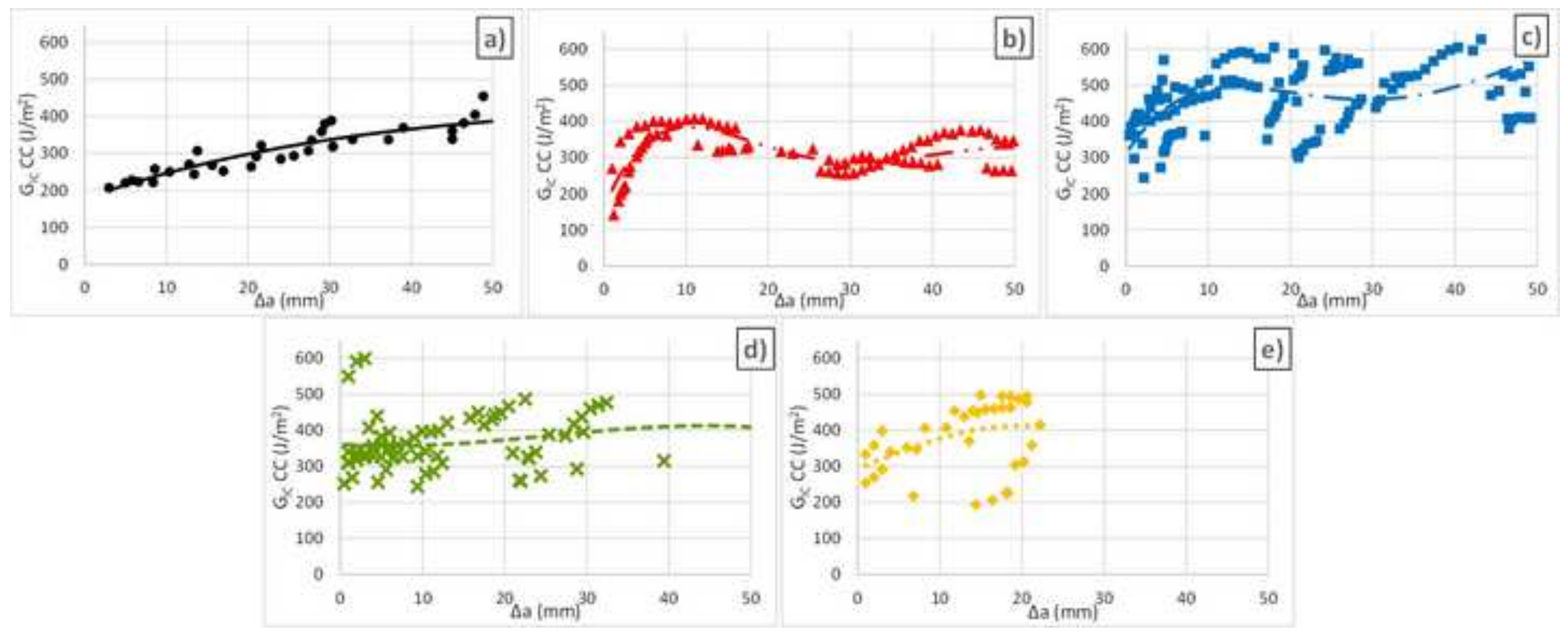
Figure 8
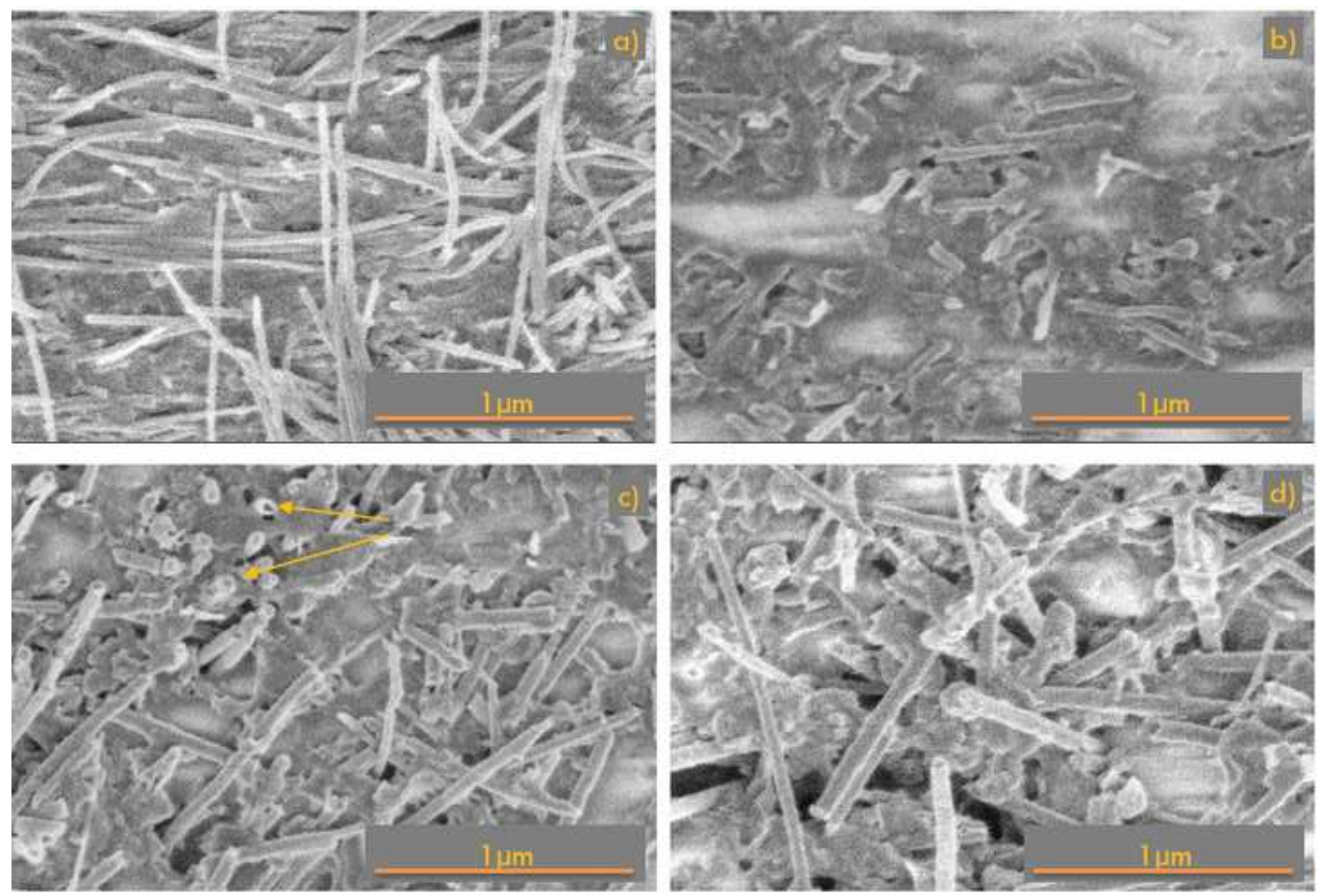
Figure 9

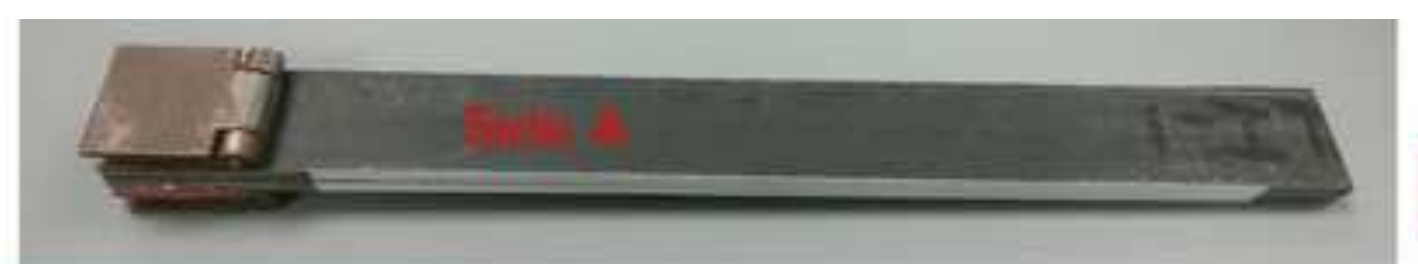

\section{0x Optical Microscope Images}

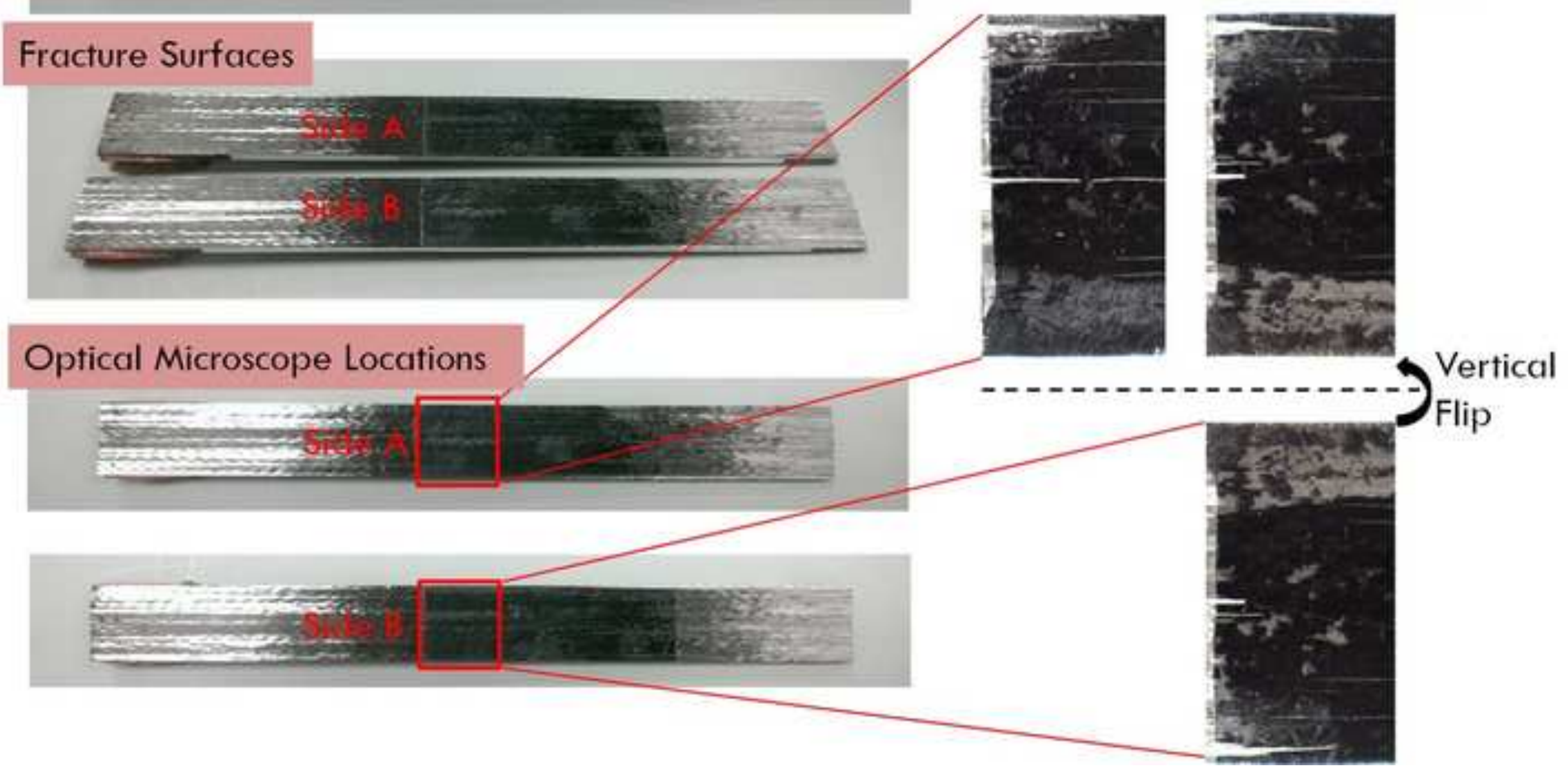


Figure 10

Internal interleaf propagation; Nanotube failure

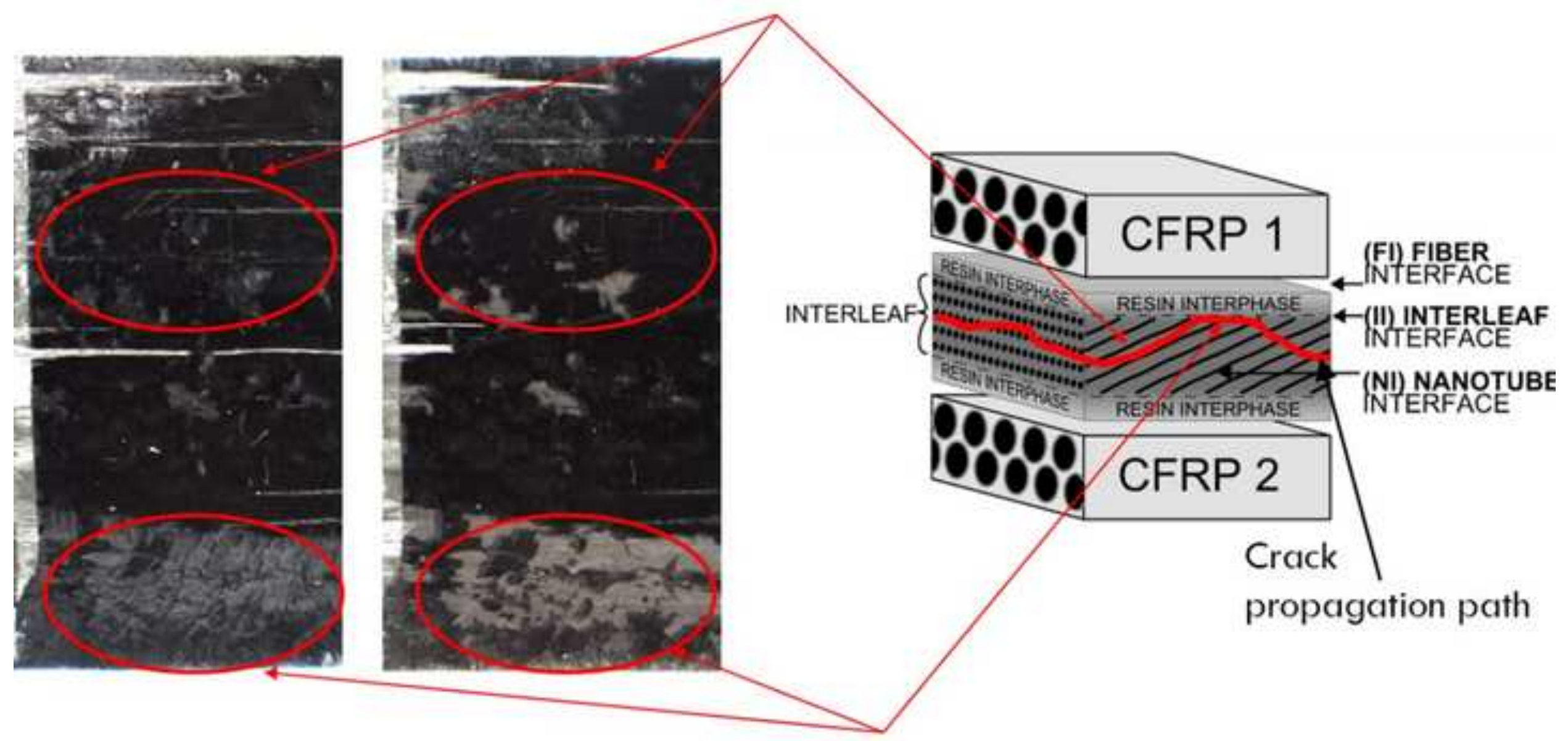

External interleaf propagation;

Resin interphase/Interleaf interface failure 


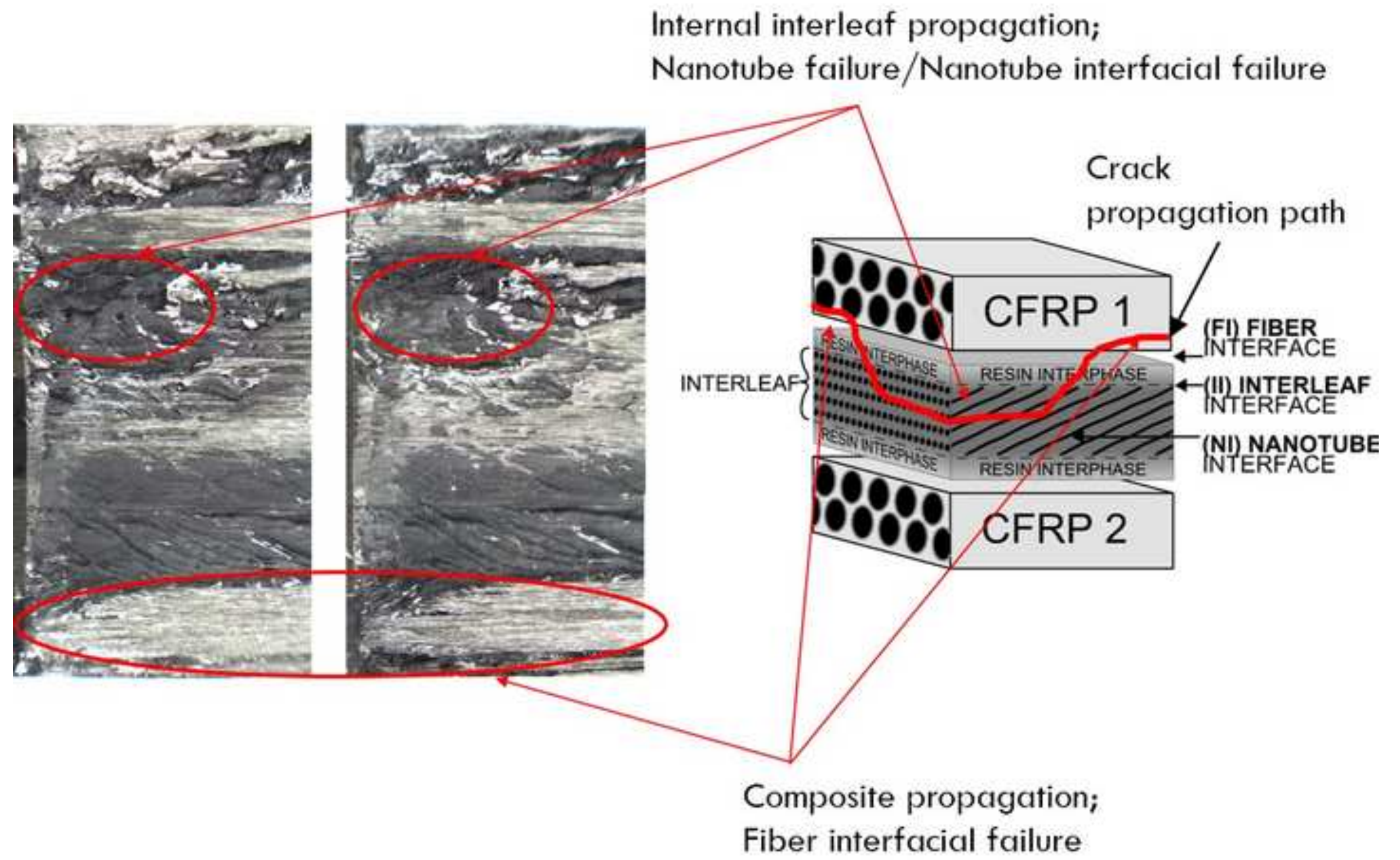


Figure 12
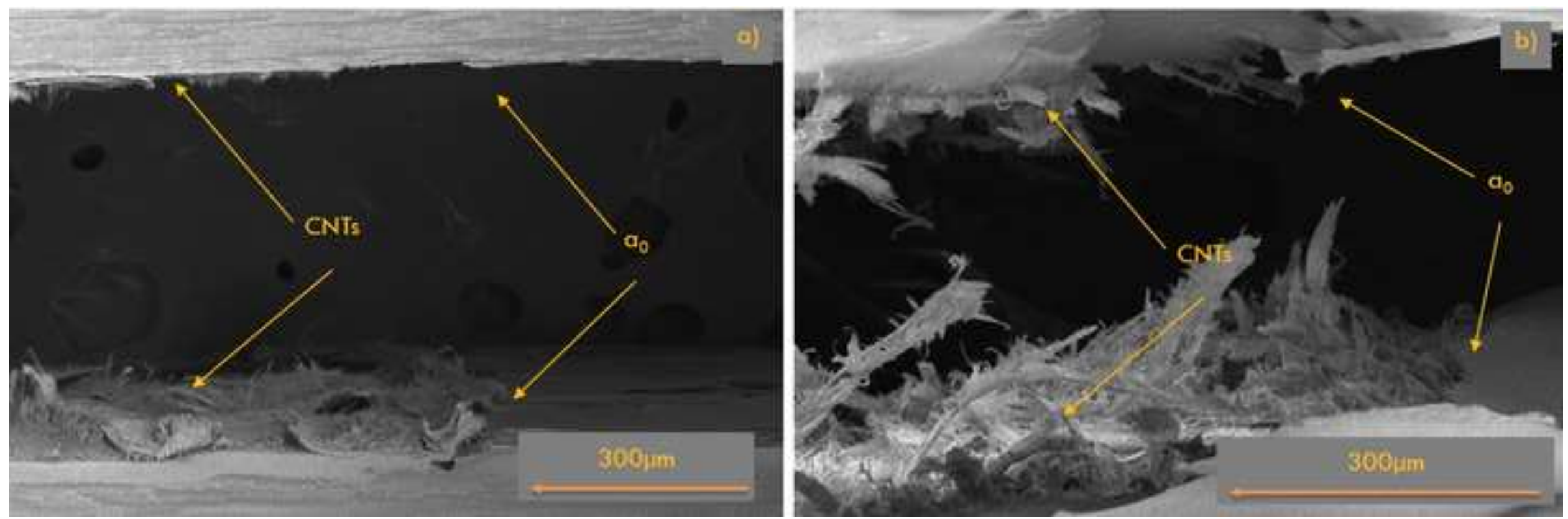
Figure 13

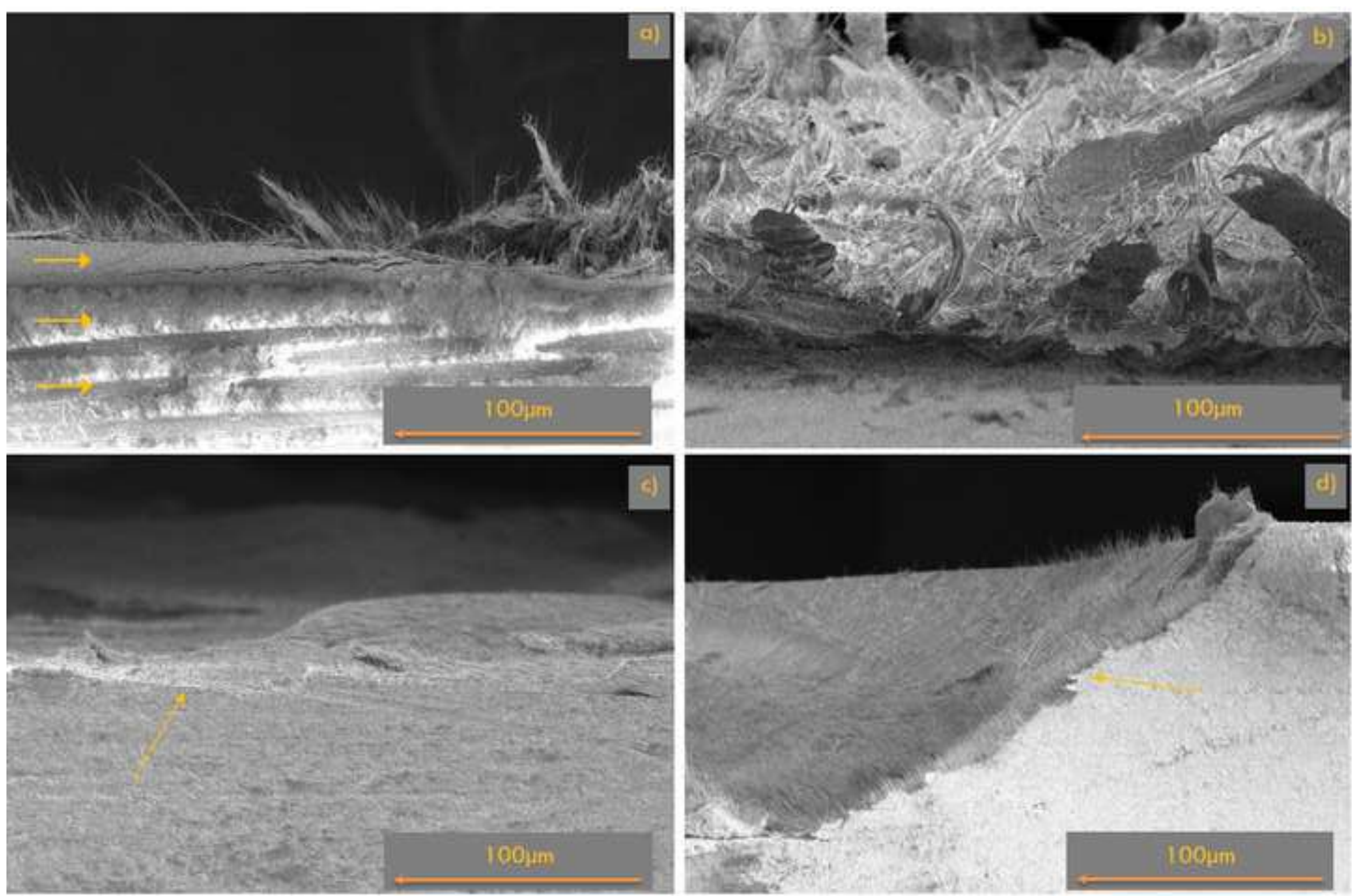


Figure 14
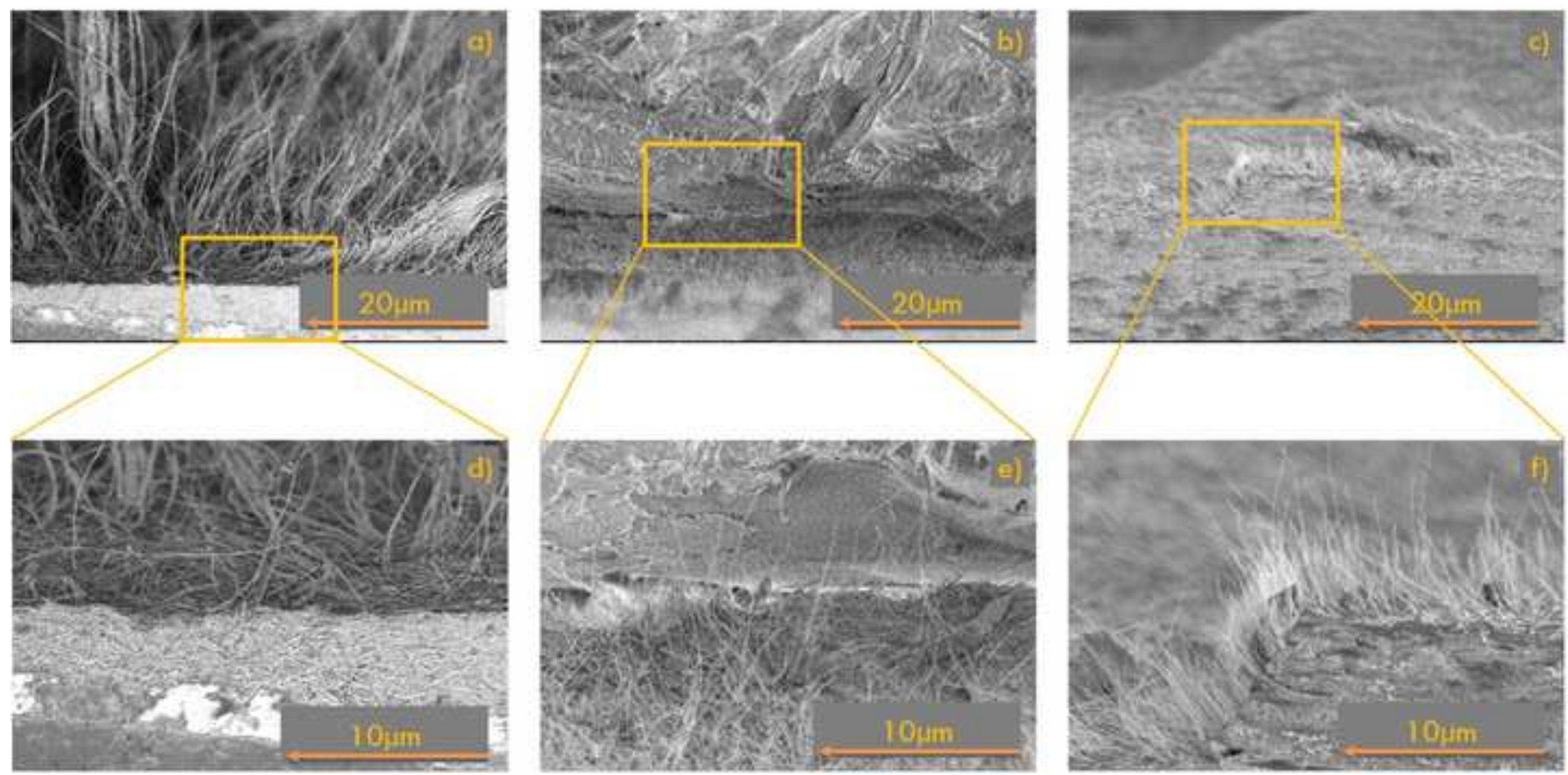